\title{
As leis fundamentais da evolução jurídica
}

\author{
Spencer Vampré
}

Ha ainda hoje, no mundo dos juristas, quem negue a possibilidade de se formularem leis gerais da evolução do direito. Parece a tais negativistas que o mundo jurídico se nos apresenta arbitrário na sua formação e nos seus elementos essenciais. Para eles a legislação não seria mais que um conjunto de regras, sugeridas pela mente criadora de deputados, de Ministros, ou de chefes de Estado.

Toda tentativa de formulá-la em princípios imutaveis provar-se-ia, assim, abortiva e infrutífera. 0 mesmo sucederia em cada país. Daí uma diversidade infinita e irredutivel de normas, a complicar ainda o problema, principalmente quando tomamos aspectos de civilização separados por grande estensão de espaço ou tempo, quando, por exemplo, comparamos as atuais instituições do Brasil com as de uma remota tribu africana, ou de uma população nômade das florestas da Oceania. $O$ espírito do investigador, pretendem ainda os negativistas, nada de comum encontra entre tantas formas jurídicas, de modo que é sonho vão formular princípios que a todos encadeie, em pontos de vista sintéticos.

Derrocado o velho conceito de um direito natural, quer como regras ou faculdades universalmente reconhecidas, quer como súmula de direitos essenciais, implícitos em todas as legislações - demonstrado que, sob uma ou outra forma, esse conceito não corresponde a nenhuma realidade, - mais se acentuou o cepticismo dos que não creem na possibilidade de normas gerais da evolução jurídica. E, todavia, o 
problema se impõe, necessariamente, a tal ponto que, sem uma solução afirmativa, toda investigação científica, no domínio do direito, seria infecunda e meramente arbitrária. Se, com efeito, o fenômeno jurídico não obedecesse a regras fundamentais, se as leis dependessem tão só do arbítrio dos seus iniciadores, se, como disse Montesquieu, um graus mais de longitude ou de latitude determinassem a mais profunda diferença da legislação, vã e ilógica se nos antolharia toda investigação científica nesse domínio. Só é possível ciência do que é constante, daquilo que é constante dentro da variação dos fatos. Se os princípios científicos são relações necessárias entre antecedentes e consequentes, formuladas pelo espírito humano, só pode haver princípios quando a variabilidade dos fenômenos não é infinita, mas dentro dela subsiste qualquer coisa que não varie.

Aqui está precisamente o campo da ciência - descobrir o que ha de normal e constante na diversidade imensa dos fatos de observação. Os fenômenos passageiros da matéria, que denominamos fenômenos físicos; os fenômenos mais profundos, que apelidamos fenômenos químicos, e os complexos fenômenos que chamamos biológicos, ou sociais, todos se apresentam em multiformes aspectos, parecendo, á primeira vista, pela variedade mesma das suas manifestações, irredutiveis a cânones gerais.

Quem poderia futurar, no primeiro momento da história mental do homem, que o calor e a luz, o movimento e a eletricidade, o som e o magnetismo, a hidráulica e a gravitação universal, seriam explicaveis com o subsídio de algumas leis de Newton, de Kepler, de Archimedes, de Galileu, e de dois ou três gênios tutelares das ciências físicas? Quem poderia imaginar que a série multiforme desses fenômenos que se desdobram multiformemente em outros tantos fenômenos secundários, se reduziriam a algumas leis que os explicam e os acorrentam logicamente ao espírito do homem? O mesmo diríamos da química, da biologia, da psícologia, da sociologia ou da moral. 
O mesmo diríamos dos fenômenos jurídicos: - a variação dos códigos legislativos não impede, antes pressupõe, como na física, a existência de princípios fundamentais, que os elucidam e que os reunem num todo lógico.

Usemos de um símile. Quem percorre uma rua, quem penetra numa cidade, divisa aspectos os mais diversos na fórma das habitações humanas, como de resto a maior diversidade nos trajes, nos gestos, nas opiniões, nos sentimentos, em suma, nas fórmas da atividade mental ou física. Seria, porém, insensato, afirmar, por exemplo, que tais casas não correspondem a nenhum princípio, dada a diversidade de suas formas. Todos sabemos que, quaisquer que sejam as variações ditadas pelo capricho dos proprietários ou pelo gênio dos arquitectos, todas obedecerão a regras construtivas, que derivam diretamente de leis científicas; as da física, quanto á gravidade, á resistência dos materiais, á disposição das traves, arcos, etc.; as da química, quanto á composição da argamassa, dos revestimentos, das ferragens, das tintas, etc.; as da higiene, quanto ás dimensões, arejamento e insolação dos cômodos, drenagem do solo, etc.

Todos sabemos, pois, que, dentro da maior liberdade quanto ao plano geral de cada edifício, e quanto ao seu custo e gôsto estético, subsiste estricta obediência ás normas da arte de construir, cujos preceitos práticos, por sua vez, decorrem de normas científicas.

Pois bem. Fenômeno idêntico se verifica quando comparamos as várias legislações dos povos. Todas, qualquer que lhe seja o grau de desenvolvimento, obedecem a princípios fundamentais; todas se plasmam pelos mesmos cânones. $\mathrm{E}$, do mesmo modo que a mais humilde cabana, construida no mais remoto rincão da Africa, deve obedecer ás mesmas regras de estabilidade que sustentam um arranhacéu na Quinta Avenida de Nova York, assim tambem entre a mais primitiva legislação de uma tribu australiana e a mais recente criação jurídica do Brasil ou da Alemanha, ha um nexo que as une, um mesmo principio que as norteia e que torna possível a investigação científica. Não será 
buscando nos conceitos metafísicos um direito natural, não será formulando teorias especiosas e complexas, que haveremos de descobrir esse princípio, mas sim na observação direta do que se passa perto de nós, sob nossos próprios olhos. Quando Newton formulou a gravitação universal, sugerida pela maçã que diante dele caiu ao solo, colheu, sem sair do seu jardim, a verdade fundamental que revolucionou a astronomia, a física e com ela toda a ciência humana. Busquemos a verdade em nosso próprio jardim, observando em torno de nós, e induzindo dos fatos mais triviais as leis que revelam. Partamos da idéia de que em torno de nós, ao alcance de nossos próprios olhos, estão as leis que buscamos. Se as acharmos, como espero, teremos o consolo de ver o presente, o passado e o futuro, pois a ciência possue esse espelho mágico, em que se reflete o que é, o que foi e o que será. Não o tivesse, e todo o seu trabalho resultaria inoperante. Queremos compreender o que vemos, para provar o que veremos, e para reconstituir o que viram nossos avós.

Se as acharmos, com esse tríplice reflexo no presente, no pretérito e no porvir, acharemos, ao mesmo tempo, mil formas de comprová-las, que aqui estão patentes, e que, entretanto, não foram percebidas ou não geraram consequências.

Mas, entremos em matéria. Essas leis supremas, ou, melhor, essa suprema lei que explica o dia de hoje, o de hontem e o de amanhã, é a lei de toda atividade humana, de toda atividade vital - o princípio do mínimo esfôrço. Eis a sua fórmula: todo homem (e poderiamos dizer todo ser vivo) tende a obter o máximo de resultado com o menor esfôrço possível. Todo homem, e todo o ser, se orienta, em última análise, para a mais alta afirmação de sua espécie. Afirmação da existência individual, afirmação da vida da espécie, aí estão, em duas fórmulas aparentemente simples, todos os dramas da vida orgânica, todas as tragédias da existência humana. 
Como se vê, este conceito filia a filosofia jurídica ás grandes correntes da biologia e da ciência em geral.

Não poderemos, neste momento, salientar tal filiação senão indiretamente: o contrário nos distrairia da rota que demandamos. Entretanto, não poderemos deixar de notar que as leis fundamentais do mundo vivo são as leis da adaptação ao meio e da seleção natural, que assim formularemos: vive o indíviduo e a espécie, que melhor se adaptam ao meio; triunfam o indíviduo e a espécie mais fortes, isto é, melhor adaptados ao meio.

Esta fórmula é a mesma do mínimo esfôrço, pois adaptar-se ao meio é esfôrço menor do que lutar contra ele, luta que só raramente termina com a transformação do meio pelo indivíduo, sendo mais comum o aniquilamento do indivíduo pelas condições hostis do meio a que se não adaptou.

Assim se vê, num relance de olhos, que o princípio do mínimo esfôrço domina as leis evolutivas do mundo biológico.

Antes de proseguirmos, uma observação: não é velha, como o mundo, a asserção de que todos buscamos o prazer, e fugimos á dor, asserção em que inúmeros filósofos do passado e do presente têm repousado as suas doutrinas?

Pois bem, prazer e dôr não significam mais do que maior ou menor esfôrço neste sentido, de que todos, instintiva ou concientemente, fugimos á dôr, e buscamos o prazer, expandindo, ou procurando expandir, por este modo, a nossa vida como indivíduo e como espécie. E tão sabiamente misturou a Providência o prazer e a dôr, que os máximos prazeres e as dores mais fundas se relacionam intimamente com a existência individual e da espécie, e, para salvar esta última, sofre o indivíduo a dor mais atroz, e até sacrifica a própria vida. Mas, ainda aqui, se impõe, paradoxalmente, a lei do menor esfôrço, pois á dor de morrer para salvar um filho sobrexcede a de não o haver tentado; o esfôrço, que o pai fez e que o levou á morte, contanto que o salvasse, é menor do que a desgraça de vê-lo inanimado, sem haver tido a coragem de correr em seu auxílio. 
Tão forte, tão inelutavel, é o princípio do mínimo esfôrço, que em qualquer fato vulgar nos formula instantaneamente ao espírito, como um áto reflexo, como um movimento instintivo.

A lei do mínimo esfôrço é a lei fundamental do mundo econômico. O que chamamos oferta e procura não são mais do que economia de esfôrço. Todo vendedor pretende vender o mais caro possivel; todo comprador pretende comprar o mais barato. A lei que a ambos rege é a mesma; mas os efeitos são contrários. Cada um, no seu ponto de vista, que se contrapõe ao do outro, quer realizar o menor esfôrço possivel, ou obter a maior soma de prazer, consistente para aquele no melhor preço e para este na melhor coisa como qualidade, como quantidade, ou como esfôrço de aquisição.

O mesmo diremos de todos os valores econômicos. O operário visa o maior salário possivel, trabalhando o menos possivel; o patrão aspira a maior soma possivel de trabalho, com o minimo possivel de salário. Do choque dessas tendências, todas as lutas; da cooperação inteligente destes dois polos da atividade, todo o progresso.

Adivinha-se como estas considerações se podem desdobrar infinitamente, abarcando toda a economia política. Deixê-mo-las por enquanto, e apresentemos alguns exemplos da lei do mínimo esfôrço, como princípio de psicologia e de moral.

Esta irmã de caridade, que abandonou as galas do mundo, o vaidoso trato dos salões, os coxins do custoso automovel, o faiscar dos diamantes que lhe refulgiam na fronte, nos braços e no colo; esta alma iluminada de piedade, que fechou os ouvidos aos ditirambos do amor e recalcou os sonhos de um lar feliz, em que a alegria cantasse como um canário; esta pobre irmã de caridade, inclinada agora sobre um doente coberto de chagas físicas e, talvez pior, de chagas morais, que busca? A que lei obedecem seus atos? Que movel a impulsiona em seus anseios? 
A lei suprema do prazer; do prazer que é nobreza, e que é renúncia; do prazer que troca as galas transitórias do mundo pela bem-aventurança eterna na contemplação do supremo bem; o prazer místico, que nasce da dor, como um lírio de um pântano; o prazer divino de ser bela, da beleza da alma, beleza cem vezes melhor que a vulgar beleza do corpo; o prazer humano de ser melhor, e mais util, que o comum das mulheres, e afirmar, no sacrifício diuturno da vida, a deliciosa certeza de viver com Jesus.

Este homem de ciência, que vela as noites na contemplação dos astros, ou nas cansadas pesquisas do laboratório, este homem que foge aos reclamos do amor e aos gostos do convivio social, para sepultar-se vivo em meio da matéria inerte, este que arrisca a segurança e o bem estar para descobrir alguma coisa de novo, a que estímulo se movimenta, que meta procura, que mundos quer conquistar?

Quer achar uma lei que simplifique o trabalho mental do homem, quer adquirir um conceito inédito, que revolucione a ciência, quer afirmar, através de um esfôrço fecundo, o seu final domínio sobre um problema; quer o aplauso dos contemporâneos, ou a glória perante os vindouros, duas recompensas, quasi sempre ingênuas e vasias, com que os homens de ciência - crianças românticas — se envaidecem e se contentam.

Mas o comum dos homens, suinos morais, costuma chafudar-se na lama vulgar que se chama dinheiro, orgulho, mando, vaidade. Aqui lhes reside o regalo, o gôsto apurado, o requinte do deleite; aqui põem toda a sua alma tão contaminada de sentimentos grosseiros e inferiores que se endureceu como a pele do rinoceronte. Daí este espetáculo eterno e tremendo para a filosofia humana: de um lado, a irmã de caridade, de outro a alma de Shylock; de uma parte a renúncia de São Francisco de Assis, de outro a fascinação avara do ouro, tão despótico senhor, sobre as almas pequenas, como escravo mísero perante os corações generosos. 
Todos buscam o prazer, todos fogem á dor, todos gravitam em torno do menor esfôrço. Mas, do mesmo modo que a ação da gravidade faz descer e faz subir os corpos, atira-os ao charco, ou fá-los pairar nas alturas, segundo a impulsação das fôrças que da gravidade derivam, através do engenho humano, isto é, através do domínio da inteligência sobre a matéria bruta, assim tambem na escala dos prazeres uns tendem para os porões, e para a escuridade, outros se alçam e se libram na plena luz do sol claro.

E ainda como a lei da gravidade, que não é mais do que um aspecto da gravitação universal, resume a teoria mecânica da Terra e do Universo, assim tambem o princípio do mínimo esfôrço explica os movimentos contraditórios da psicologia humana, que se degrada ou se sublima, que se enlameia ou se irisa de luz, que é argila ou partícula do éter, que é pantanal, ou que é clarão.

As leis físicas são paradoxais, porque produzem a ação e a reação, o equilíbrio e o movimento, a energia e o repouso; esmagam e libertam; descem e sobem; são dínamos e explosão, trabalho e ruina, vida e morte. Assim, tambem, nas leis inelutaveis, que presidem á psicologia e á moral humana: - a mesma lei que faz subir, faz descer; o mesmo cầnon que redime, condena; a mesma voz que perdoa, semeia ou ampara, tambem, castiga, assola e mata, do mesmo modo que o mesmo princípio físico que produz o trabalho feraz tambem espalha a cegueira, a guerra e a destruição. A tendência ao prazer, aspecto do mínimo esfôrço, impulsiona o trabalhador incansavel como Thomas Edison, ou faz dormir sobre os bancos de uma praça o vadio que não encontra ocupação. A mesma tendência atira á podridão das sargetas a que julgou encontrar na abjeção dos sentidos a satisfação de sua vaidade de mulher, ou o sonho de ouro com que sonhou, e arremessa ás sublimidades do ascetismo essas almas sedentas de fé que passam pelos charcos da vida, em contacto permanente com o vício, mas sem que uma mancha siquer lhes contamine a virginal pureza. 
Lei do prazer, lei do menor esfôrço, que és todo um drama, que envolves cem mil dramas; que és toda um princípio, que envolves cem mil princípios; que és toda a vida moral e intelectual da Terra, e junges, na expressão larga de teus postulados, o que fizeram, o que fazem e o que farão todos os homens; lei do prazer, lei da dôr, lei do menor esfôrço, tu regeste os povos, que pela primeira vez pisaram a face do planeta; apontaste-lhes o caminho das migrações, e com elas as guerras e as conquistas, espalhando em tua passagem a morte, a viuvez e a orfandade; subiste os degraus dos tronos e sobre eles te assentaste, e do alto dos palácios senhoriais oprimiste as populações submissas e as sujeitaste a tributos e capitulações infamantes. A glória das pirâmides e dos jardins babilônicos, dos Parthenons e dos Colyseus, dos mausoléus e das colunas votivas, dos arcos triunfais e das inscrições graníticas, essa glória é tua porque tu te afirmaste no humano espetáculo através de imperadores, de reis e potentados, de nações e de homens de todas as castas que julgavam sujeitar tudo ao seu arbítrio ou ao seu mando, e não faziam mais do que obedecer-te.

E como regeste o passado, reges o presente. Esses que s̀e lançam agora na desabalada conquista do ouro e da r1queza material, que buscam senão a sujeição aos teus ditames? Esses outros que se engalfinham em torno dos postos de comando, que mais fazem do que inclinar-se, sabujos ás tuas ordens? $\mathrm{E}$ aqueles mesmos que se deliciam nos prazeres divinos da ciência e da arte, seguem todos, pobres pécoras passivas, o teu báculo incontrastavel. Buscai o prazer, aqui está a sentença que Deus escreveu na inteligência do homem; mas buscai o melhor prazer, aqui está o que lhe segredou no coração. E esta voz, dita em segredo, não a escutam todos os humanos; esta palavra, balbuciada apenas, é a palavra da suma verdade, a que nem todos atendem. E por isso o mundo rola na tragédia dos prazeres, em que se acotovelam a virgindade e o vício, a inocência e o crime, a ambição e a renúncia, o egoismo e a caridade, a podridão e o aroma, o espinho e a rosa, o mal e o bem. 
Buscar o melhor prazer é a lição da cultura e da educação moral, como o é na vida das sociedades o substituir o trabalho mecânico pelo trabalho mental. Quereis saber qual a diferença entre um réprobo e um santo? Vêde os seus prazeres, e, na escala de suas gradações, tereis sentido o abismo que os separa: para este a vida é dedicação; para aquele é violência; para este é solidariedade, para aquele é egoismo; para este é auxilio mútuo, pela palavra e pelo ato; para aquele é extorsão e roubo, por atos, por intenções e por palavras.

Quereis saber qual a diferença entre o homem venturoso e o desgraçado? Examinai o grau de educação de cada um, isto é, o modo por que se comportam na luta contra o meio ambiente. Aquele é a expressão da energia que reage sobre o próprio ser moral e físico; este se descorajou de si mesmo, e por isso se tornou indiferente ou molesto aos homens, já que o mundo é a expressão da energia e da coragem moral, e todos se sentem tentados a abandonar, ainda pela lei do maior prazer, ou do mínimo esfôrço, os que não contam sequer consigo.

Ser educado é ser feliz, porque é devassar horizontes morais mais vastos do que a mísera contingência de uma hora; é sonhar com a madrugada e com o clarão do sol em meio das tempestades da noite caliginosa; é esperar o germinar das sementes após as noitadas de inverno; é recolherse na própria dôr, que purifica como a chama dos altares e que ilumina como os clarões que nos veem da fé.

Diferença entre o educado e o inculto, eis o que determina essa distância infinita em que estão a rectidão e a perversidade, a honra e o crime, o templo e o cárcere, a glória e a infâmia, o sorriso e a lágrima, a bênção e o gemido, a luz e a treva.

Quando educamos, orientamos os corações e as inteligências, á imitação dos nobres exemplos e á prática das virtudes que honram a humanidade. Ora imitar não é senão acompanhar a linha do menor esfôrço. Entre deliberar e imitar, imitar é sempre o mais facil. Entre esco- 
lher um caminho, moral ou físico, e imitar os que nos precederam, tudo nos inclina a seguí-los. Quando, numa escola, apontamos á juventude gestos memoraveis, induzímo-la a praticá-los; quando numa academia lhe expomos certa doutrina, indicamos-lhe imitativamente a atitude mental do seu autor em frente a dado problema, e a concitamos a manter essa mesma atitude.

Todo progresso humano se realizou, se realiza, e se realizará pela imitação ou pela invenção. Imitamos todas as vezes que adotamos uma nova teoria científica ou um novo aparelho de produção industrial ou econômica. Imita o pensador, ao adotá-lo, um novo credo, religioso ou filosófico. Imitamos, todos nós, ao receber novos trajes ou novas atitudes mentais. Tudo quanto se denomina instrução ou educação, na mais larga expressão destes conceitos, se reduz a imitar os bons exemplos, seguindo as regras consideradas salutares; e isso mesmo quando se deseja a instrução ou a educação mais livre do espírito de tradição.

Foi a imitação que nos ensinou a língua que falamos, os habitos sociais, as demonstrações de afecto, de respeito, ou de pudor, que compõem o drama da vida social. Não necessitaremos demonstrar tal asserção mais compridamente por agora. Mas, não basta a imitação, para assinalar o progresso humano. E' necessária a invenção a qual ocorre sempre que alguem, por uma idéia abstracta, ou por uma realização material, econômisa esfôrço, ou consegue maior soma de prazer ou redução da dor.

Quem verificou que a ingestão de certo remédio aplacava o sofrimento, ou abreviava a cura, realizou uma invenção terapêutica. Quem descobriu que com o emprego de uma alavanca poderia levantar pesos maiores do que com o auxílio dos braços, conseguiu uma invenção que, através da teoria das alavancas, foi o germen de grande número de máquinas modernas e possibilitou a expansão das formidaveis indústrias contemporâneas. Quem encontrou o alfabeto, e combinou, por uma admiravel intuição, as idéias 
e os sinais gráficos, economizando o esfôrço da memória e permitindo a transmissão do pensamento através do espaço e do tempo, pôs á disposição da humanidade um dos mais poderosos elementos de seu progresso mental.

Examinemos todas as conquistas do homem, no domínio das invenções, e veremos que todas versaram sobre economia do esfôrço. Do tear mecânico á locomotiva, do barco a remo ou á vela, ao trasatlântico e ao aeroplano, tudo, todo o progresso se resumiu em ef etuar maior produção com maior economia de esfôrço, de segurança, de confôrto, de tempo ou de espaço, que tudo isso se compreende na economia do esfôrço. Assim, tambem as invenções psicológicas, morais e jurídicas.

O monoteismo é uma invenção em relação ao politeismo, como este o foi em relação ao animismo, porque significa uma simplificação de conceitos, um menor esfôrço mental, uma concepção mais compreensiva e mais larga; do mesmo modo que a descoberta de Copérnico simplificou a complexa astronomia de Ptolomeu, e as leis de Lavoisier fizeram desaparecer de golpe as mais estranhas e complicadas doutrinas alquímicas.

Assim, na esfera do direito, longo tempo a humanidade imitou e imitará, até encontrar um novo processo de economia de esfôrço. Foi assim que, durante séculos, o direito romano imperou como lei, e a imitação das instituições jurídicas desse povo admiravel constituiu a preocupação dominante dos príncipes e dos sábios.

Quando, porém, se formulou o Código Napoleão, e com ele a generalidade de princípios que caracteriza as codificações modernas, no mesmo momento se operou uma economia imensa de esfôrço, pela simplificação correspondente dos preceitos.

Residiu neste fato a razão íntima da decadência do direito romano como lei escrita. O Código Napoleão constituiu por isso monumental invenção jurídica. $O$ mesmo díríamos de grande número de suas teorias, como a dos 
fatos juridicos em geral, a dos contratos e a da responsabilidade extrancontratual.

Não precisamos dizer que, por facilidade de linguagem, temos considerado a imitação e a invenção como fatos instantâneos e decorrentes de um cérebro. Na realidade os movimentos mentais da humanidade se realizam por lentas aluviões e estratificações, só comparaveis á invisivel modificação da crosta terrestre.

Numa imitação, ou numa invenção, a colaboração coletiva sobreexcede á atividade individual, e a própria obra do gênio não é muitas vezes senão a mais alta expressão do pensamento de uma época. Mas o que nos importa sublinhar é que a imitação e a invenção constituem apenas dois aspectos da lei do mínimo esfôrço.

No ponto de vista estrictamente jurídico, a imitação exerce influência dominante na formação e adoção das leis. Razão tinha Gabriel Tarde em transformá-la no centro de irradiação do seu pensamento filosófico. Quando o legislador edita uma norma, sugere e obriga a sua imitação. A própria expressão "norma", "regra" ou "lei", significa aquilo que é a conduta regular, normal ou constante dos homens probos, que constituem a média da moralidade social.

Que veem a ser as sanções legais, mais do que fatores de determinação psicológica, tendentes a que todos se conformem com essas normas, que a lei concretiza? Que sentido têm as mais enérgicas dessas sanções, - as de natureza penal - senão como meios de adaptação dos indivíduos ás regras de conduta regular, isto é, como meios de compelir á imitação do que praticam os morigerados e os honestos?

Assim, na origem mesma da norma, se obedece á necessidade de economizar o esfôrço. A sociedade humana não subsistiria um momento sequer, sem o princípio da imitação, isto é, com a faculdade de cada um agir como entendesse, sem o dever de imitar a média dos seus concidadãos, sem conformar-se á regra ou norma, de sua conduta. 
Compreende-se, portanto, que quando se fala em imitação, se alude ao menor esfôrço, ao maior prazer, que poderíamos subdistinguir em maior segurança, em maior comodidade, em maior rapidez, em uma palavra, em maior justiça.

Obedecessem todos espontaneamente ao princípio de imitação dos bons, e toda a vida social se desenvolveria como mínimo esfôrço individual e coletivo. Não teriam os homens necessidade de interromper a sua atividade produtiva para realizar esse trabalho de readaptação dos díscolos e dos criminosos. Notemos, de passagem, que, para maior felicidade humana, o número de atentados á lei de imitação, ou do mínimo esfôrço, é proporcionalmente pequeno e, com os progressos da educação jurídica dos indivíduos e dos povos, será cada vez menor.

A necessidade das leis e dos tribunais, escreveu uma vez Savigny, é a mais flagrante demonstração da nossa incultura moral. Tinha razão o mestre. Para muita gente, para a generalidade dos individuos, os tribunais e as leis. não existem praticamente: - toda a sua vida jurídica e moral se desenvolve sem a intervenção dos juizes e dos advogados, pela fé da palavra dada, pela execução leal do que contrataram e pelo respeito ao direito alheio. Só uma fracção mínima das relações de direito vão a esses hospitais jurídicos, que se chamam Tribunais ou Côrtes de Justiça, do mesmo modo que só uma fracção insignificante das populações se socorre dos hospitais e médicos. Ou melhor: - a maior parte dos cidadãos goza saude normal, ou resolve os seus problemas de saude, ou de higiene, com as próprias forças.

Tambem no terreno jurídico, a maior parte das relações se realiza sem a intervenção de processos judiciários, sendo mais comum se acordarem as partes, fieis ao provérbio de que mais vale um mau acôrdo do que uma boa demanda, - outra fórma indireta do mínimo esfôrço, segundo. a qual, sem deshonra ou grave prejuizo material, é preferivel transigir a demandar. 
Aqui está outra questão fundamental: - a da origem ou razão de ser da demanda ou do processo, série de atos e formalidades com que pedimos aos juizes o reconhecimento de nossos direitos. Cada homem sente a necessidade de expandir-se irrestrictamente, estendendo a sua atividade o mais possivel, em relação aos seus semelhantes, e ás coisas de que tenha interêsse de apropriar-se. No exercício desses atos, a atividade de cada um vai até o ponto de defrontar-se; de limitar-se com a atividade dos outros. Daí a norma, como limitação, e daí o sentimento geral das normas, como imitação dos atos praticados em tais conjunturas pelos varões modelares.

Travado o conflito de atividade, ou, melhor, postas em jogo essas normas de limitação, surge o combate judiciário, de que Ihering nos deu o quadro empolgante, combate cuja expressão mais vulgar nos apresentam dois antagonistas que se empenham em luta corporal. Como aspectos dessa luta, quando o organismo do Estado ainda se não formou, ou se não consolidou, a história do direito registra o talião, a vingança privada, a dação noxal, a escravidão por conquista ou por dúvida, o wehrgeld, o duelo, o juizo de Deus, etc., - fórmas todas de reparação ao direito violado, todas explicaveis pela lei do mínimo esfôrço, se considerarmos que é essa lei que as sugere e as dita, para evitar a incerteza das relações jurídicas, determinada pela indefinida possibilidade de represálias.

Em todas essas manifestações, ora luta o indíviduo sózinho, para obter o respeito ou a reparação dos seus direitos, ora tem a seu lado os membros da tribu, os cidadãos da cidade, as testemunhas dos pactos ou contratos, e, finalmente, os órgãos do Poder Judiciário.

Verifica-se, aqui, a linha de evolução do direito: - ela se realiza sempre no sentido do minimo esforço, isto é, facilitando progressivamente a cada um a maior solidariedade social na defesa dos seus direitos. Comparai qualquer sociedade primitiva com a fase atual das instituições proces- 
suais do Brasil, e vereis que ao passo que lá, o titular de um direito violado tem de lutar sozinho, ou quasi só, para restabelecê-lo, aqui toda a máquina se põe a seu lado para cooperar com ele. Todos compreendemos, intuitivamente, que é muito menor o esfôrço de recorrermos á autoridade judiciária, para dirimir uma contenda sobre nossos direitos do que nos defendermos á mão armada. O processo judicial é, em sua essência, uma cristalização do menor esfôrço na defesa dos direitos. Ele se moldou sobre a luta, a princípio no terreno físico, e depois no terreno mental. Nas sociedades primitivas, todo processo é uma luta, um combate, a princípio real, depois simulado; nas sociedades modernas é ainda um combate, com as armas da razão: - a ciência da lei; a lógica dos argumentos. E do mesmo modo que primitivamente se escolhiam campeões para sustentar a luta, ou para auxiliá-la, assim vão hoje os pleiteantes á cata dos mais provectos advogados para lhes sustentar as pretensões. Tocamos aqui numa outra lei de evolução jurídica, que poderiamos chamar, a exemplo de Freud, de lei da sublimação, lei segundo a qual se passa do ato físico ao ato mental, da realização material ao símbolo, em uma palavra, do concreto ao abstrato. Demos ha pouco um exemplo com o processo, que passou de luta corporal a luta de inteligências.

Encontraremos outra comprovação nos rituais e nos símbolos que compõem o direito antigo. Tirai aos povos, que nos precederam, os seus ritos e símbolos, e nada podereis compreender de sua vida e de sua história. E' que, nas primeiras fases da civilização, os homens sentem concretamente e não podem separar cada ato de sua fórma material.

Ninguem demonstrou melhor esta tese, do que lhering, no "Espírito do Direito Romano"

Para os povos que não aprenderam ainda a arte da palavra escrita, ou quando é ainda incipiente, pouco generalizada, só o símbolo guarda a recordação do que se passou, só ele fixa essa enunciação da vontade irrevogavel, que gera ou transfere direitos ou obrigações. 
E' notavel, a respeito, a comparação dos símbolos, mesmo de duas épocas as mais afastadas e extremes de todo contacto aparente.

Quando assinamos hoje um documento em duplicata, ou quando passamos uma escritura em tabelião, da qual se podem extrair certidões, praticamos o mesmo ato que, ha mais de três mil anos antes de Cristo, praticavam os assírio-babilônios, súbditos do rei Hamurabi, ao cortar um ladrilho em dois fragmentos, que se completavam, constituindo cada um deles um pedaço do escrito em que se havia contratado. Reproduzimos (é verdade mais completamente) o mesmo ato que os romanos, ao cortarem um ramo de arvore em dois pedaços (stipulum), cada um dos quais era guardado por cada contratante na presença das testemunhas, como sinal e manifestação do contrato ou estipulação.

Os símbolos contratuais, consistentes em beber juntos (spondere, beber á saude, de onde tambem sponsus, o noivo, e sponsor, o promitente); em apertar as mãos, em voga em quasi todos os povos; em banquetear-se como celebração de alegria e de paz, símbolo usual em todas as agremiações, das mais incultas ás de mais delicada cultura, todos sintetizam essa comunhão de afetos e de simpatias, essa aliança e solidariedade moral que garantem a fiel execução do que se prometeu e pactuou.

Se nos não fugisse o tempo, encararíamos agora a evolução dos símbolos, para demonstrar que o direito moderno ainda participa de muitos atos e gestos primitivos e que estes representavam a princípio uma série complexa de atitudes rituais. Dessa demonstração resultaria um novo aspecto da lei do mínimo esfôrço, segundo o qual todo o símbolo resume uma série de atos materiais, de conceitos.

Estudaríamos tambem a lei da divisão do trabalho e a da especialização das funções, formas ainda da lei do minimo esfôrço.

Seria preciso passar em revista a filosofia do direito, nos seus máximos problemas, para que o meu pensamento pudesse ser apanhado em toda a plenitude. Os conceitos 
que aqui exponho venho desenvolvendo, ha algum tempo, desde quando lecionava direito romano nesta Faculdade. Nenhuma disciplina poderia ser mais propicia a tais investigações do que essa cumiada donde se divisam todos os horizontes intelectuais dos povos: nenhum levantamento topográfico poderia ser mais frutífero que o tirado dessa cordilheira de montanhas, que formou as principais vertentes mentais da humanidade.

Nem se conseguiria hoje explicar razoavelmente o direito romano sem encará-lo á luz da legislação comparada e da filosofia jurídica, e sem procurar nele, não já a lógica das disposições legais, mas as correntes profundas que moldaram o pensamento atual, e que explicam a sua evolução no passado e no presente.

Quanto mais estudo a legislação romana e com ela comparativamente a dos demais povos, mais me persuado das grandes leis evolutivas que acabei de referir, mais claramente vejo marchar sempre a humanidade no sentido que apontam.

Se ha um traço que caracteriza a evolução humana é o progresso contínuo do sentimento de solidariedade entre os homens. O problema foi posto nesta época em termos tão altos, que se considerou como caso de intervenção internacional o se denegarem, dentro de qualquer paiz, os direitos de liberdade e de propriedade, tidos como essenciais ao homem.

Sentimo-nos cada dia mais solidários no terreno econômico e moral, social e político, jurídico e étnico. Se alguem quizer saber o grau de cultura ou de civilização de um povo, examine como age em relação aos outros povos, e encontrará que o mais adiantado e o mais culto é o que maior número de relações mantém, e, por isso mesmo, o que tem mais vivo sentimento da solidariedade humana.

Pois bem, e seja este o remate de nossas considerações. Quanto mais solidários os homens, tanto mais fortes; quanto majs unidos em torno de um ideal de justiça, mais formosos e melhores. Quanto mais cooperantes no respeito ao 
direito de cada um, mais concientes de seus próprios direitos; maior economia realizam no afirmá-los e defendê-los; maior soma de prazer logram.

Não ha dor maior, para o coração humano, do que a que decorre de uma injustiça. E só existe uma satisfação maior do que ver a justiça realizada: - é haver concorrido para a sua realização.

E' o respeito aos princípios; é a imitação dos exemplos salutares; é o mínimo esfôrço na ordem ética, assinalado pela recta moral do dever, que representa a maior soma de felicidade possivel.

No dia em que os estadistas o compreenderem; no dia em que os homens todos o praticarem, a Paz descerá sobre o mundo, e a Justiça se elevará, tão pura e alta, tão cintilante e tão bela, que ha de iluminar com o seu clarão todos os recantos da Terra, e será abençoada e será louvada, porque a soube dignificar e engrandecer. 